\title{
The awareness and authenticity of gastronomic tourism in Ilocos Region
}

\author{
Etrata, Richard M. \\ Ilocos Sur Polytechnic State College, Philippines (richard.etrata1523@yahoo.com)
}

Received: 10 July 2021

Revised: 25 August 2021

DOI: $10.5861 /$ ijrsm.2021.m7730

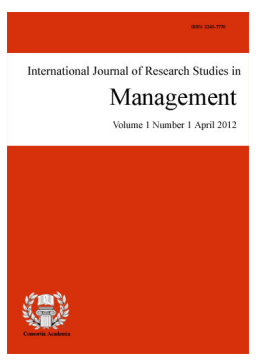

ISSN: $2243-7770$

Accepted: 26 September 2021

\section{Abstract}

Gastronomy is an important part of tourism and provides a strong image with a unique attraction for the region in developing the destination, under pressure from the tourism competition. This study aimed to propose a framework of gastronomic tourism in Ilocos region. Specifically, present the profile of the respondents; determine the factors affecting gastronomic products' potential; identify the impacts of gastronomic tourism, evaluate the gastronomy destination; to test the significant difference among the responses when grouped according to profile; test the significant relationship among three major variables; and propose a framework for gastronomical tourism. The researcher employed the descriptive research method. The survey instrument consisted of items intended for the profiling of the respondents and utilized a 4-point Likert type scale. A sample size of 395 local and foreign tourists travelling in Ilocos Region were used in the study. Frequency distribution, percentage, weighted mean, Independent sample T-test, Analysis of Variance and Pearson Product Moment Correlation were used as statistical tools. Based on the result, Majority of the respondents are female, belong to the age bracket of 26-40 years old; are local tourists, leisure seekers and travel once a year. The most familiar Ilocano dish is Longanisa; Gastronomic product has potential attractiveness in terms of preserving cultural heritage, adding destination authenticity value, marketing, motivation and gastronomy destination; Gastronomic tourism has impact in Ilocos region in terms of economic, social and cultural aspects; The respondents have an excellent gastronomic experience and they are satisfied with the food they eat when they visited the Ilocos region; There is a significant difference on assessment of the factors affecting gastronomic potential attractiveness, impact of gastronomic tourism and gastronomy destination when grouped according to profile; Highly significant relationship exists between gastronomic products potential attractiveness, impacts of gastronomic tourism and gastronomy destination. Highly significant relationship also exists between impacts of gastronomic tourism and gastronomy destination and A framework of gastronomic tourism in Ilocos Region that is patterned after the findings of this study is hereby proposed.

Keywords: authenticity, gastronomy, Ilocos region, impacts and food and culinary tourism 


\section{The awareness and authenticity of gastronomic tourism in Ilocos Region}

\section{Introduction}

Gastronomy tourism is described by the United Nations World Tourism Organization (UNWTO) and the Basque Culinary Center (BCC) as "a form of tourism activity characterized by the visitor's experience linked to food and related products and activities while traveling." Along with authentic, traditional, and/or innovative culinary experiences. Gastronomy tourism is an integral part of local life that is formed by a territory's history, culture, economy, and society. It has a potential to enhance the visitor experience by providing a direct link to the city, its people, history, and heritage (World Tourism Organization and Basque Culinary Center, 2019).

Gastronomy is one of the most prevalent tourist attractions. Everyone enjoys learning about the local cuisine in a certain destination through visiting its restaurants, having a taste of the regional specialties, and participating in unexpectedly memorable experiences. As gastronomy has evolved into a deliberate sector in many destinations, it contributed to the creation of wealth and jobs by providing additional value to the value chain as a whole. It also has evolved from the development of high-quality food to its transformation to the hotel or tourism industry as well as the promotion of the country's trademark (Aizega, 2019).

Ilocos Norte, Ilocos Sur, La Union, and Pangasinan are the four provinces that make up the Ilocos Region, also known as Region I. Ilocos Region is a well-known place of heritage sites, coastal attractions, and wonderful handicrafts but it is always the food and gastronomy that loiters in the minds of visitors. It is recognized for its strong culinary traditions and a salt-happy and porcine-dominated regional cuisine. Since Ilocano cuisine is also a progressive cuisine, the traditional ways meet new age techniques and interpretations without sacrificing the integrity of its food customs. Today, the Ilocano people have preserved cooking methods that are fresh, simple, abundant in flavor and healthy. That is why Ilocano dishes have this certain charm that takes it to spotlight.

One of the key obstacles to quantifying gastronomy tourists and calculating the effect of gastronomy tourism internationally is the lack of a well-defined and standardized concept of gastronomy tourism as well as a methodology for comparisons. The findings of the study will be used by the researcher to create a more important structure that best explains gastronomic tourism in the Ilocos Region, which can be used by local governments, social researchers, anthropologists, and sociologists to better understand how food is related to culture, as well as tourism and rural growth. Moreover, gastronomy tourism embraces a wide range of tourism services. It has caused a rise in the enjoyment and opportunities to be informed provided by high-quality local gastronomy products in different locations, as well as the activities available in their production and processing environments (WTO, 2019).

In addition, it provides tremendous prospects for the whole sector and the society at large. But it's also a rapidly developing world, making it more important to prepare and identify strategies that set the course for both existing and new gastronomy tourism destinations. The study's findings are intended to help with various main aspects of planning and management of gastronomy tourism destinations in the Ilocos Region. Martin et al. (2019) mentioned that the five topics that limit the study of gastronomic tourism are motivation, authenticity, history, management and marketing, and destination. The first principle that limits gastronomic tourism is motivation, which takes into account factors such as experience and health concerns. The second is authenticity, which is an important aspect of a place's gastronomy production and a driving force for tourism promotion. Thirdly, there is an investigation in the relationship between culinary processes and culture, and gastronomy is emphasized as a component of the local community's cultural heritage (Lopez-Guzman et al., 2017). In the fourth position, it is important to consider how the location's management and promotions are carried out, including basic aspects such as customer behavior; and, in fifth place, the analysis of the relationship between gastronomy and a particular destination. 
Gastronomy, as part of cultural tourism, provides tourists with new tastes and flavors of local cultures, as well as educational opportunities (Widjaja et al., 2020). Furthermore, indigenous places can also have a good reputation that incorporates their distinctive cuisine and cultural values. In addition, gastronomy tourism plays an important role in providing visitors with enjoyable and unforgettable experiences by leveraging the destination's cultural heritage. Gastronomy tourism's appealing ability has become a key strategic feature in the tourism and hospitality industries. As a result, tourism destinations are increasingly relying on their culinary assets to set themselves apart from their competitors (Kumar, 2019).

Consequently, this broadsheet is conceptualized to present a scrutiny of the gastronomy as an emerging sector of the tourism industry. It shows awareness with the term gastronomy rather than food or culinary tourism. Ilocanos will be enlightened in terms of the different concepts and elements of gastronomic tourism. The study provided theoretical implications as well as practices, since the hospitality and tourism companies of the Ilocos Region benefit from knowing the importance of the local gastronomy as elements of interest for the tourist. The interest level of tourists in tasting and getting to know the local gastronomy includes the culinary variable becoming another tool for the advancement and tourist competitiveness of a certain places. It must be borne in mind that gastronomy forms a part of the cultural inheritance of the destination, in both its tangible characteristic such as the raw materials or ingredients used and its intangible facet such as the taste.

\subsection{Objectives of the study}

This study aimed assess the gastronomic tourism in Ilocos region. Specifically, it determined the factors affecting gastronomic products' potential attractiveness in terms of preserving cultural heritage, adding destination authenticity value, marketing, motivation and gastronomy destination; identified the impacts of gastronomic tourism in terms of; economic aspect, social aspect and cultural aspect; evaluate the gastronomy destination in terms of gastronomic experience and satisfactions; tested the significant relationship among three major variables;

\section{Methods}

Research Design - The researcher employed the descriptive research method. In this study, the researcher utilized an adopted questionnaire and conducted interview to local and foreign tourists. Questionnaire refers to a research instrument, in which a series of question, is typed or printed along with the choice of answers, expected to be marked by the respondents, used for survey or statistical study.

Respondents of the Study - A sample size of 395 local and foreign tourists travelling in Ilocos Region were used in the study. Having the total tourist arrival of 2,262,274 as of 2019, considering 5\% marginal error and 95\% confidence level using Raosoft sample size calculator. The main respondents of the study are the travelers who visited Ilocos Region as a tourist either residents or non-residents.

Instrument - The survey instrument consisted of three sections and utilize a 4-point Likert type scale. The anchors include Strongly Agree, Agree, Disagree, and Strongly Disagree. The questionnaire to be used is an adaptation of the studies of De Castro et al. (2015) entitled "Culinary Tourism as a Destination Attraction in the Province of Batangas, Philippines", Galvez et al. (2017) entitled "Gastronomy as an Element of Attraction in a Tourist Destination: A Case of Lima, Peru" and Martin et al. (2019) entitled "A Fuzzy Segmentation Study of Gastronomic Experience" which were aptly modified to suit the purpose towards which this study will be conducted. The questionnaire underwent reliability test to ensure the dependability and consistency of the test. This test is indispensable before any survey questionnaire can be used.

The reliability test was employed to a total of 30 respondents considered as tourists travelling to Ilocos Region. It is showed that the Cronbach's Alpha test of the questionnaire indicated an acceptable result Preserving Cultural Heritage 0.796, Adding Destination Authenticity Value 0.831, Marketing 0.952, Motivation 0.899, Gastronomy Destination 0.775, Economic Impacts 0.816, Social Impacts 0.863, Cultural Impacts 0.928, 
Etrata, R. M.

Gastronomy Experience 0.908 and Satisfactions 0.891. Thus, the questionnaire is valid and reliable.

Data Collection Procedure - With the use of the official website of the Department of Tourism Regional Office I, the researcher sent a request letter indicating the intent to conduct the survey. There are some tourists both local and foreigner who positively responded the questionnaire through an online google form. The researcher also visited restaurants, gastronomic producers and food and wine centers to conduct the actual administration of survey and interview within the given span of time. In addition, the researcher made used of purposive sampling. The main goal of purposive sampling is to focus on particular characteristics of a population that are of interest, which enabled the researcher to select the group of respondents that would answer the research questions.

Data Analysis - Weighted mean was used to assess the factors affecting gastronomic product potential attractiveness in terms of preserving culinary heritage, adding destination authenticity, marketing, motivation and gastronomy destination, impacts of gastronomical tourism in terms of economic aspect, social aspect and cultural aspect and gastronomy destination in terms of gastronomic experience and satisfactions. In addition, inferential statistics such as independent sample t-test and Pearson Product Moment Correlation were used to test the hypotheses of the study.

Ethical Considerations - Before the distribution of questionnaires, the researcher informed the respondents about the nature of the study and discussed the purpose and objectives of the study. The consent of the respondents was then humbly sought. The researcher assured them of the utmost confidentiality of their identities. Hereafter, respecting the ideas and opinions of the respondents and recoding their advice on the research topic can ensure a prolific study. The researcher also discussed and incorporated the intellectual property rights and was able to tap ethical resources to avoid ethical dilemmas.

\section{Results and Discussions}

\section{Table 1.1}

Factors affecting the potential attractiveness of gastronomic products in terms of cultural heritage preservation

\begin{tabular}{|c|c|c|c|}
\hline Indicators & WM & $\mathrm{VI}$ & Rank \\
\hline 1. I value the local cuisine which was influenced by past generations of the Ilocanos & 3.56 & SA & 1 \\
\hline 2. I visit Ilocos Region because of authentic dishes & 3.42 & A & 3 \\
\hline 3. I love how Ilocanos preserved their authentic dishes & 3.51 & $\mathrm{SA}$ & 2 \\
\hline Composite Mean & 3.50 & SA & \\
\hline
\end{tabular}

Table 1.1 presents how respondents perceive the factors affecting gastronomic products potential attractiveness in terms of preserving cultural heritage with the composite mean 3.50 interpreted as strongly agree. Findings presents that most of the respondents are attracted with the local cuisine of Ilocanos which was preserved and influenced by past generations. The authenticity of Ilocano dishes remains steadfast because of the resilient preservation of Ilocanos cultural heritage. It was inherited from generation to generation. The variations of pinakbet dish remains the same as it uses the traditional fish sauce unlike with other regions. In addition, Ilocos Empanada of Vigan and Batac still uses the traditional grated papaya fillings and longanisa mixtures. Thus, preserving the cultural identity of Ilocano dishes and locally produced wines are contributors to the rapidly increasing demand of tourism industry in Ilocos Region. Giving value to the authentic cuisine which was affected by past generations of the Ilocanos (3.56) rank the highest followed by loving how Ilocanos preserved their authentic dishes (3.51). Ilocos Region preserves cultural heritage to strengthen the tourism industry of the four provinces. As a result, tourists appreciated the Ilocano cuisine influenced by past generations. The preservation of authentic Ilocano dishes manifests the rapidly increasing number of tourists in the region. As a matter of fact, Ilocos Bagnet, Empanada, Longanisa, Igado and Pinakbet are the well-loved authentic dishes in the region. 
However, visiting Ilocos Region due to authentic dishes" garnered the lowest mean rating of 3.42 interpreted as agree. It implies that respondents have different preferences in terms of visiting a gastronomy destination. The discovery of new dishes affects the interest of the respondents yet the preservation of cultural heritage is valued by the tourist. According Ivanov and Seyituglo (2020), a good gastronomic identity is critical because it increases the number of high-quality tourists in a region and allows visits to take place throughout the year, preserving cultural heritage while also promoting economic and socio-cultural growth. In the interview conducted by the researcher, most of the local producers and vendors are continuously practicing the preservation of the authentic dishes. This is not only to instill the authenticity of the Ilocano dishes but also to help local producers to have an income and livelihood as well. For instance, the used of fermented fish sauce is evident to ethnic restaurants rather than fusion of foreign or commercially produced ingredients.

\section{Table 1.2}

Factors affecting the attractiveness of gastronomic products in terms of adding value to the authenticity

\begin{tabular}{llll}
\hline \multicolumn{1}{c}{ Indicators } & WM & VI & Rank \\
\hline 1. I prefer to buy innovated authentic dishes that will give more value to the food. & 3.36 & A & 2 \\
2. I like to eat heirloom food that will give more value to the food. & 3.34 & A & 3 \\
3. I love how Ilocanos give value to their authentic dishes. & 3.55 & SA & 1 \\
& Composite Mean & 3.42 & Agree \\
\hline
\end{tabular}

Table 1.2 explains how respondents perceive the factors affecting gastronomic products potential attractiveness in terms of adding destination authenticity value with the composite mean of 3.42 interpreted as agree. It implies that most of the respondents agree that authenticity of gastronomy destination and products draw an interest to every tourist. Respondents value the Ilocano dishes offered by traditional restaurants and food shops in the region. As a matter of fact, the local gastronomic culture directly up with the history of the region as well as with the soul of its people and rhythm of daily life. In addition, most of the Ilocano dishes are housed in a traditional restaurant that really represents the ancestral concepts of a destination. For example, the Ilocos Empanada and Okoy were very popular in the streets of Calle Crisologo and along Paoay Church of Ilocos Norte.

Among the items cited, the love of Ilocanos in giving value to authentic dishes (3.55) rank the highest followed by the preference to purchase innovated authentic dishes that gives more value to the food (3.36). Tourists nowadays are food enthusiasts and experience seekers that is why they love visiting Ilocos Region. Thus, Ilocanos value the authenticity of local dishes to make their tourist experience the traditional Ilocano foods. However, eating native delicacies that gives more value to the food garnered the lowest mean rating of 3.34 interpreted as agree. It implies that tourist behavior greatly affects the curiosity of respondents to eat traditional Ilocano dishes. As cited by De Castro et al., (2018), it is hard to present an interpretation of local nourishment into an asset in business improvement. Providing local nourishment to meet the needs of businesses. Stock or readiness practices for local sustenance encounters- that is, being made available (sorted out, developed, packaged, and shared for guest use, and, obviously, such local sustenance encounters should be sought after by sightseers in order to be monetarily viable from a long-term perspective.

\section{Table 1.3}

Factors affecting the potential attractiveness of gastronomic products in terms of marketing management

\begin{tabular}{lccc}
\hline \multicolumn{1}{c}{ Indicators } & WM & VI & Rank \\
\hline $\begin{array}{l}\text { 1. I see Ilocos Region as a gastronomical tourism destination. } \\
\text { 2. I like how Ilocanos promote the destination through gastronomy. }\end{array}$ & 3.45 & $\mathrm{~A}$ & 2 \\
$\begin{array}{l}\text { 3. I will recommend Ilocos Region to my peers because of Ilocanos authentic local } \\
\text { cuisine }\end{array}$ & 3.49 & $\mathrm{~A}$ & 3 \\
& Composite Mean & 3.46 & 1 \\
\hline
\end{tabular}

Table 1.3 enumerates the perceptions of the respondents on the factors affecting gastronomic products potential attractiveness in terms of marketing. The table reveals that the respondents show an "Agree" level on 
the marketing factors affecting the gastronomic tourism of Region 1 with an overall mean rating of 3.46. Result shows that Ilocos region is a potential gastronomy destination. As a matter of fact, gastronomy tourists acclaim the gastronomic experiences to other travelers. When taken singly, recommending Ilocos Region to peers due to Ilocano authentic local yields the highest mean rating of 3.49 with an "Agree" level followed by seeing Ilocos Region as a gastronomical tourism destination with the mean rating of 3.45. This implies that gastronomy tourists travelling to Ilocos Region share the importance of Ilocanos authentic local cuisine to other tourists through word of mouth.

This is very much reflected on the paper of Sahin (2015) stating that gastronomy tourism is a type of tourism that appeals to high income and intellectual tourists, aged between 35 and 55, who want to visit destinations of different food cultures, who are open to new experiences such as food, to share their experiences with others and spend much. In the marketing of destinations, the gastronomy tourism creates important power with its potential for year-round performance, increases in spending and staying time over other types of tourism, contributes to local development, environmentally sensitive development, authentic and inimitable product range exclusively in this region. In the destination and curve of life the gastronomy tourism has a leading power between discovery and the period of decrease in demand (Sahin, 2015). However, the promotion of gastronomy destination of Ilocanos garnered the lowest mean rating of 3.43 inferred as agree. This implies that the marketing strategies to promote gastronomy tourism in Ilocos region is not well managed. Thus, some Ilocano dishes are not familiar to tourist. Native dishes are distinct sources to create, implement, and market a destination in today's marketing environment, where there is intense competition. Marketing of destinations is a dynamic phenomenon, as it has several difficulties with various reasons and expectations (Yousaf, 2017). Tourists visiting a destination should be included in regional culture in all respects as gastronomic tourism is considered an integral and reflective part of improving and marketing a destination

\section{Table 1.4}

Factors affecting the potential attractiveness of gastronomic products potential in terms of motivation

\begin{tabular}{lccc}
\hline \multicolumn{1}{c}{ Indicators } & WM & VI & Rank \\
\hline 1. I like to discover the flavor of the local food. & 3.53 & SA & 1 \\
2. I prefer to transmit my experiences with the local food & 3.44 & A & 3 \\
3. I want to advise other travelers about gastronomic experiences in Ilocos Region & 3.47 & A & 2 \\
& Composite Mean & 3.48 & Agree \\
\hline
\end{tabular}

Table 1.4 presents how respondents perceive the factors affecting gastronomic products potential attractiveness in terms of motivation. The table shows that the respondents agree on the motivation factors affecting gastronomic tourism with a composite mean of 3.48. This implies that tourists are motivated to travel because of the authentic Ilocano dishes. As a matter of fact, most of the tourists want to discover the traditional dishes offered by specialty and ethnic restaurants in the region. In addition, most of the respondents advise other travelers to visit Ilocos Region because of their gastronomy experiences.

Taken singly, discovering the flavor of the local food yields the highest mean rating of 3.53 followed by advising other travelers about gastronomic experiences in Ilocos Region" with a mean rating of 3.47. Gastronomic tourism is now seen as one of the most important commitments for improving or consolidating those tourist destinations, owing to the growing importance that travelers place on knowing more about gastronomic culture. In reality, some travelers regard visiting a specific restaurant or simply learning more about the cuisine of the Ilocos Region as the primary motivation for their journey. Moreover, gastronomic tourism is tourism in which the tourist's primary motive is food, and although it may not be able to produce its own flow, it may add value to a visit by providing the opportunity to live an experience that takes tourists closer to the population visited. However, transmitting experiences with the local food" garnered the lowest mean rating of 3.44 showing an "Agree" level. Result also shows that respondents don't prefer much to transmit their gastronomy experiences with the local dish. This implies that tourist behavior affects the gastronomy product potential attractiveness in terms of motivation. Stanley, (2019) made mentioned that gastronomy tourism is a 
The awareness and authenticity of gastronomic tourism in Ilocos Region

form of tourism experience in which tourists sample local cuisine in restaurants, sample street foods, take cooking lessons, and visit local food markets, food exhibits, and festivals in new locations. It includes visitors who travel with the primary goal of sampling local cuisine as their primary motivation (i.e., primary motivation) and others who travel with local cuisine sampling as a side pursuit (i.e., secondary motivation) of their holiday.

\section{Table 1.5}

Factors affecting the potential attractiveness of gastronomic products in terms of gastronomy destination

\begin{tabular}{lccc}
\hline \multicolumn{1}{c}{ Indicators } & WM & VI & Rank \\
\hline 1. I love how Ilocanos developed traditional restaurants and food markets & 3.52 & SA & 2 \\
2. I like how Ilocanos conduct gastronomy festivals & 3.53 & SA & 1 \\
3. I visit Ilocos Region because of the street markets, local products, delicatessens & 3.44 & A & 3 \\
and wine cellars. & Composite Mean & 3.49 & A \\
\hline
\end{tabular}

Table 1.5 enumerates the perceptions of the respondents on the factors affecting gastronomic products potential attractiveness in terms of gastronomy destination. The table states that the respondents show an "Agree" level on the gastronomy destination factors affecting the gastronomic tourism of Ilocos Region with a composite mean of 3.49. It implies that Ilocos Region is one of the most visited places in the Philippines in terms of gastronomic destination. The conduct of gastronomy festivals and presence of traditional restaurants, food markets and shops are some of the reasons why gastronomy was established in the whole region.

When taken singly, the conduct of Ilocos region's gastronomy festivals" yields the highest mean rating of 3.53 with an "Agree" level followed by how Ilocanos developed traditional restaurant and food markets with the mean rating of 3.52 and "I visit Ilocos Region because of the street markets, local products, delicatessens and wine cellars" with the mean rating of 3.44. Result shows that tourists are travelling to Ilocos Region because of the annual celebration of gastronomy festivals such as Longanisa festival, Bangus festival and Bagnet festival. Gastronomic tourists want to experience the local dishes offered and presented during the celebration of the different gastronomy festivals.

On the items cited, visiting Ilocos Region because of the street markets, local products, delicatessens and wine cellars" got the lowest mean rating of 3.44. This implies that frequency of travel affects the gastronomy product potential attractiveness of the region. The "once in a year" travel of tourist's manifest in the gastronomy experiences of the respondents. Furthermore, Gastronomy is now recognized as a deciding factor in drawing visitors when they are deciding where to visit. Gastronomic tourism has the potential to become a stand-alone tourism type in addition to sun and sea destinations, as well as a supporting activity for these destinations. There are two perspectives in order to describe the concept of gastronomic tourism (Cruz et al., 2019). The first is concerned with tourist research and discusses the study of tourist behavior and motivation. The second aspect of gastronomic tourism examines the destination itself and looks at four different aspects: different forms of tourism, infrastructure in the destination, tourist goods, and destination promotion based on gastronomy.

\section{Table 2.1}

Impact of gastronomic tourism in terms of economic aspect

\begin{tabular}{lccc}
\hline \multicolumn{1}{c}{ Indicators } & WM & VI & Rank \\
\hline $\begin{array}{l}\text { 1. Gastronomic tourism provides a variety of jobs for the residents in Ilocos } \\
\text { Region }\end{array}$ & 3.49 & ME & 1 \\
$\begin{array}{l}\text { 2. Gastronomic tourism creates local businesses such as traditional restaurant } \\
\text { and food shops }\end{array}$ & 3.48 & ME & 2 \\
3. Gastronomic tourism brings more investment to the community's economy & 3.44 & ME & 4 \\
4. Gastronomic tourism improves the residents' quality of life. & 3.45 & ME & 3 \\
5. Gastronomic tourism raises the price of products and services & 3.38 & ME & 5 \\
& Composite Mean & 3.45 & ME \\
\hline
\end{tabular}

Table 2.1 presents how respondents perceive the beneficial impacts of gastronomic tourism in Ilocos Region 
economically. The table shows that the respondents agree "To a Moderate Extent" on the different favorable economic impacts of gastronomic tourism in Ilocos Region with a composite mean of 3.45. The respondents generally agree that gastronomic tourism contributes immensely to the overall economic welfare of Region 1 . The Ilocano cuisine offered by traditional restaurants help increase beneficial impacts to both the community and residents of Ilocos Region.

The respondents agree "To a Moderate Extent" that "gastronomic tourism provides a variety of jobs for the residents in Ilocos Region" as it garnered the highest mean rating of 3.49 on the economic impacts of gastronomic tourism in Ilocos Region. It is followed by the items "gastronomic tourism creates local businesses such as traditional restaurant and food shops" with the mean rating of 3.48, "gastronomic tourism improves the resident's quality of life" with the mean rating of 3.45. This implies that gastronomy tourism contributes to the overall economic welfare of Ilocos Region. Gastronomic tourism activities may provide direct and indirect jobs as well as financial income to a destination (Sahin, 2015). These developments are positive indicators that the economic situation of the residents is improving. Tourism, according to de Albuquerque Meneguel (2019), "unquestionably creates job opportunities, new sources of income, new investment and government revenues." However, gastronomic tourism brings more investment to the community's economy" yields a mean rating of 3.44 and the price of products and services is rising as the demand for gastronomy tourism arise garnered the lowest mean rating of 3.38. This implies that the rapid growth of gastronomic tourism will lead to high demand of gastronomy products and services resulting to high prices and services offered.

\section{Table 2.2}

Impact of gastronomic tourism in terms of social aspect

\begin{tabular}{|c|c|c|c|}
\hline Indicators & WM & VI & Rank \\
\hline 1. Gastronomic tourism gives advice about gastronomical experiences to other travelers & 3.46 & $\mathrm{ME}$ & 2.5 \\
\hline 2. Gastronomic tourism increases family and friendship bonds & 3.49 & $\mathrm{ME}$ & 1 \\
\hline 3. Gastronomic tourism helps transmit my experiences with Ilocano food & 3.46 & $\mathrm{ME}$ & 2.5 \\
\hline 4. Gastronomic tourism improves the social and communication skills of the residents. & 3.42 & $\mathrm{ME}$ & 5 \\
\hline 5.Gastronomic tourism provides opportunity for residents to interact with tourists. & 3.44 & $\mathrm{ME}$ & 4 \\
\hline Composite Mean & 3.45 & $\mathrm{ME}$ & \\
\hline
\end{tabular}

Table 2.2 enumerates the insights of the respondents on the social effects of gastronomic tourism in Ilocos Region. The table reveals that the respondents show an agree "To a Moderate Extent" level on the different social impacts of gastronomic tourism with a composite mean of 3.45. This shows that respondents are all aware of how gastronomic tourism boosts the social well-being of residents in Ilocos Region.

When taken singly, gastronomic tourism increases family and friendship bonds yields the highest mean rating of 3.49 with a "To a Moderate Extent" level followed by gastronomic tourism gives advice about gastronomic experiences to other travelers and gastronomic tourism helps transmit my experiences through Ilocano food with the mean rating of 3.46 respectively, The item "gastronomic tourism increases family and friendship bonds" shows that most of the respondents are family oriented and experience seekers. It conforms to the socio demographic profile of respondents regarding age. Wherein, generation $\mathrm{Y}$ tends to be more adventurous and the capability to travel is more stable compared to other generations.

Gastronomy is a way for a group to communicate symbolically. It uses sensory experiences to relay messages about race, faith, status, and identity. Tourists can immerse themselves in the aspect of otherness of a culture in both sensory and intellectual ways by eating at a destination. Aside from having an exotic and exceptional touristic experience, visitors can discover the local culture of a destination by tasting exotic food or having an unusual gastronomic experience (Long et al., 2018). Moreover, the items "gastronomic tourism provides opportunity for residents to interact with tourists" with the mean rating of 3.44 and "gastronomic tourism improves the social and communication skills of the residents" shows a least development as to the communication skills of Ilocanos. This implies that there is no proper training particularly on Filipino and English language. Thus, further development of social and communication skills of the residents is needed. 
The awareness and authenticity of gastronomic tourism in Ilocos Region

Table 2.3

Impact of gastronomic tourism in terms of cultural aspect

\begin{tabular}{lccc}
\hline \multicolumn{1}{c}{ Indicators } & WM & VI & Rank \\
\hline 1. Gastronomic tourism increases my knowledge about Ilocano culture & 3.52 & GE & 1 \\
2. Gastronomic tourism offers a unique opportunity to understand local culture & 3.50 & GE & 3 \\
3. Gastronomic tourism preserves cultural values. & 3.51 & $\mathrm{GE}$ & 2 \\
4. Gastronomic tourism generates better understanding of differences in culture. & 3.46 & $\mathrm{ME}$ & 5 \\
$\begin{array}{l}\text { 5. Gastronomic tourism helps keep Ilocano culture alive and helps maintain the } \\
\text { ethnic identity of the local residents. }\end{array}$ & 3.47 & $\mathrm{ME}$ & 4 \\
& & & Composite Mean \\
\end{tabular}

Table 2.3 presents the overall responses of the respondents on the cultural impacts of gastronomic tourism in Ilocos Region. It shows that the good cultural impacts of gastronomic tourism in Ilocos Region have a composite mean of 3.49 with a "To a Moderate Extent" level. This implies that most of the respondents agree on all the possible cultural impacts that may be related to gastronomic tourism.

Taken singly, item "gastronomic tourism increases my knowledge about Ilocano culture" earned the highest mean rating of 3.52 with a "To a Great Extent" level. It is succeeded respectively stating that "gastronomic tourism preserves cultural values" with the mean rating of 3.51 and "gastronomic tourism offers a unique opportunity to understand local culture" with the mean rating of 3.50. Result shows a positive response as to the preservation of cultural heritage. However, items "gastronomic tourism helps keep Ilocano culture alive and helps maintain the ethnic identity of the local residents" with a mean rating of 3.47 and "gastronomic tourism generates better understanding of differences in culture" with a mean rating of 3.46 yielded a "To a Moderate Extent" level. It signifies the confinement of respondents with gastronomy experiences. This implies that gastronomy tourism is a sub category of cultural tourism. The involvement of the whole cultural tourism is not evident in the study that is why some of the respondents cannot weigh the overall cultural impact as to the understanding of differences in culture. Culture, as a component of gastronomic tourism, is commonly described as people's inner desire to learn about other cultures. Gastronomic tours are organized to introduce a region's dishes and food culture, which play a significant in tourist selection and experience, can highlight a region.

Table 2.4

Summary table on the impact of gastronomic tourism

\begin{tabular}{llccc}
\hline & Indicators & WM & VI & Rank \\
\hline 1. Economic Aspect & & 3.45 & ME & 2.5 \\
2. Social Aspect & & 3.45 & ME & 2.5 \\
3. Cultural Aspect & & 3.49 & ME & 1 \\
& & Overall Mean & 3.47 & ME \\
\hline
\end{tabular}

Table 2.4 reveals that the impacts of gastronomic tourism measured along economic aspect, social aspect and cultural aspect are found to have a "To a Moderate Extent' level of responses supported by the overall mean of 3.47. Result shows that gastronomy tourism in Ilocos Region provides a great impact as to economic, social and cultural aspects. In terms of economic aspect, it creates variety of job opportunities to Ilocanos such as the establishment of traditional and specialty restaurants, food shops showcasing the One Town One Product (OTOP) of every municipality and city of the region, production of fruit wines such as grapes, dragon fruit, mango and bugnay and celebration of gastronomy festivals such as Longanisa Festival, Bangus Festival and Bagnet Festival. As to social aspect, gastronomy tourism strengthens family and friends bonding and leisure activities while in terms of cultural aspect, it increases the knowledge of both tourists and residents as to the preservation of Ilocano cuisine. The effects of gastronomy tourism are huge and can enhance any country's overall economy. Tourists tend to continue demanding more traditional foods because they are made more authentic by the admittance to cultural and historic heritage of the different cultures. As a result, food and drink is becoming more important and certain social groups take higher priority. The development of Ilocano Cuisine can enhance and exploit culinary identity and legacy as it becomes clear that food is important in building a distinct regional identity. 
Etrata, R. M.

Table 3.1

Gastronomy destination in terms of gastronomic experience

\begin{tabular}{lccc}
\hline \multicolumn{1}{c}{ Indicators } & WM & VI & Rank \\
\hline $\begin{array}{l}\text { 1. The taste of the Ilocano dishes is different from the one prepared in other } \\
\text { regions. }\end{array}$ & 3.50 & SA & 4.5 \\
2. It excites me to taste local food in its place of origin. & 3.53 & SA & 3 \\
3. An authentic experience & 3.54 & SA & 2 \\
4. Service and hospitality & 3.55 & SA & 1 \\
5. Offers genuine gastronomic products. & 3.50 & SA & 4.5 \\
& Composite Mean & 3.52 & SA \\
\hline
\end{tabular}

Table 3.1 presents the overall gastronomic experiences of respondents in Ilocos Region. It shows that the gastronomy destination in Ilocos Region in terms of gastronomic experiences has a composite mean of 3.52 with a "Strongly Agree" level. Result indicates that gastronomy destination is influenced directly by the gastronomic experiences and satisfactions of gastronomic tourists. Taken singly, service and hospitality in Ilocos Region earned the highest mean rating of 3.55 with a "Strongly Agree" level. It is succeeded respectively stating that gastronomic tourism in Ilocos Region is an authentic experience with the mean rating of 3.54 and it excites gastronomic tourist to consume local food in its place of origin" with the mean rating of 3.53. Result shows that Ilocanos are service oriented and hospitable. Every gastronomy business provides quality service to every gastronomic tourist. Restaurant employees pay attention to every tourist, listen and communicate in an understandable manner. In addition, residents are responsible to answer queries and handle complaints quickly. It implies also that Ilocanos are well trained and experienced in providing customer satisfaction.

As a result, gastronomic tourism can be described as a type of cultural tourism that permits visitors to learn about the customs and ways of life of the community they are visiting through gastronomic representations, as this encourages learning about the local culture through sensations and experiences while tasting traditional dishes. Food tourism, according to Han (2019), is linked to cultural photos, cultural attractions, food histories, activity promotion, and experience functions. However, items "the taste of the Ilocano dishes are different from the one prepared in other regions" and "offers genuine gastronomic products' yield the lowest mean rating of 3.50 respectively. Result shows that Ilocano dishes are authentic and well preserved. As a matter of fact, gastronomic experience varies in line with the customer's expectations and knowledge of gastronomy. Not all gastronomic tourists enjoy an Ilocano dish or a gastronomic experience in the same way. In addition, traditional Ilocano dishes and gastronomy products are unique and distinct as perceive by gastronomy tourists. Culinary and gastronomy is now regarded as a tourist attraction (Forleo et al., 2019). Despite of not being the sole variable that influences behavior, motivations have a significant impact on consumption. Motivations are forces that emerge as a result of an unmet need, resulting in a behavior. The tourist is motivated to travel to carry out gastronomic practices in a specific location by the gastronomic experience (which we define as the result of tasting food while taking into account factors such as the price, the atmosphere of the establishment, the professionalism of the service received, etc.). Allures such as regional cuisine, gastronomic festivals, and the offer of establishments with a variety of foods and beverages, as well as gastronomic routes and circuits, can be used to create this gastronomic experience. Culinary experiences are attracting a growing number of visitors to destinations (Wijaya et al., 2013).

\section{Table 3.2}

Gastronomy destination in terms of satisfaction

\begin{tabular}{lccc}
\hline \multicolumn{1}{c}{ Indicators } & WM & VI & Rank \\
\hline 1. Offered variety of Ilocano foods & 3.54 & SA & 1 \\
2. Good food at reasonable price (value for money) & 3.47 & A & 2 \\
3. Facilities have aesthetic design & 3.40 & A & 5 \\
4. Atmosphere and environment of Ilocano restaurants and food shops & 3.44 & A & 3 \\
5. Innovation and new flavors in the dishes & 3.42 & A & 4 \\
& Composite Mean & 3.45 & A \\
\hline
\end{tabular}

142 Consortia Academia Publishing (A Partner of Tourism Educators and Movers of the Philippines) 
Table 3.2 presents the overall responses of respondents in terms of gastronomy satisfactions. It shows that the gastronomy destination in Ilocos Region in terms of satisfactions has a composite mean of 3.45 with an "Agree" level. Result of this study implies that gastronomic tourists are very much satisfied with the gastronomy products and services of Ilocos Region. The offering of Ilocano dishes in every traditional restaurant and food shops is an indicator of a well-managed gastronomic tourism in the region.

Taken singly, the offering of different Ilocano foods earned the highest mean rating of 3.54 with a "Strongly Agree" level. It is followed by the good food at reasonable price (value for money) with the mean rating of 3.47, and the atmosphere and environment of Ilocano restaurants and food shops with the mean rating of 3.44. However, innovation and new flavors in the dishes garnered a mean rating of 3.42 and facilities have aesthetic design got the lowest mean rating of 3.40. It shows that most of the traditional and specialty restaurants are comfortable and clean yet layout and facilities are not well developed. Result shows that respondents are very much satisfied as to the variety of Ilocano dishes offered in Ilocos Region. The cultural preservation of authentic Ilocano dishes is an edge to further promote the gastronomy of the four provinces. According to Buele (2020), tourist satisfaction with a destination's gastronomy is influenced by the cultural wealth produced by these culinary processes, as well as the safe quality of the products used in their preparation, which are typically sourced from local producers. These connote special and distinct experiences from those enjoyed by the traveller in their home country. As a result, gastronomic encounters become a deciding factor in the satisfaction of travelers.

\section{Table 4.1}

Relationship between gastronomic products attractiveness, impacts of gastronomic tourism and destination

\begin{tabular}{lccc}
\hline \multicolumn{1}{c}{ Impacts of Gastronomical Tourism } & F-value & p-value & Interpretation \\
\hline Economic Aspect & $0.839^{* *}$ & 0.000 & Highly Significant \\
Social Aspect $\quad 0.844^{* *}$ & 0.000 & Highly Significant \\
$\quad$ Cultural Aspect & $0.829^{* *}$ & 0.000 & Highly Significant \\
Gastronomy Destination & & & \\
Gastronomic Experience & $0.802^{* *}$ & 0.000 & Highly Significant \\
Satisfaction & $0.774^{* *}$ & 0.000 & Highly Significant \\
\hline Legend: Significant at $p$-value $<0.01$ & &
\end{tabular}

Legend: Significant at $p$-value $<0.01$

Table 4.1 presents the correlation between the factors affecting gastronomic products potential attractiveness, impacts of gastronomic tourism and gastronomy destination. It was observed that there was a strong direct correlation between the three variables. In addition, the resulted p-values were less than 0.01 alpha level, thus the null hypothesis is rejected.This means that there was a signficant relationship exists and implies that the better the factors affecting gastronomic products potential attractiveness, the greater the impact and the better is the gastronomy destination.

The result of the study reveals the importance of proper implementation and sustainability of gastronomic product attractiveness tools. Ilocos region as a potential destination of gastronomic tourism must standardized its policies and guidelines in terms of preserving the cultural heritage of Ilocos cuisine particularly on the offering of authentic dishes for some traditional restaurants. In terms of marketing, word of mouth strategy and social media advertisements boost the popularity of Ilocos region resulting to the increase of job opportunities and employment for Ilocanos. As to gastronomy destination, the availability of various restaurants and food markets as well as celebration of gastronomy festivals such longanisa festival, bangus festival and dinengdeng festival marked the great development of Ilocos regions economic, social and cultural perspectives.

Furthermore, with the rise of cultural heritage tourism, cultural and heritage tourism has gained authenticity. Authenticity has evolved into a heritage-protection term that is intimately linked to the basis of cultural heritage. Intangible and active features influence authenticity, which appears to lean toward existentialism and constructivism. As a result, the effects of tourists' perceived happiness and interactions are investigated using a combination of positive and existential validity. Tourist destinations are the subject of constructive authenticity, 
while visitors are the focus of existential authenticity. The mechanism of cultural identification and authentic experiences of tourists in the production of intangible cultural heritage is a significant aspect of customer behavior theory, which is rooted in service quality management, and is based on tourist satisfaction.

Table 4.2

Relationship between impacts of gastronomic tourism and gastronomy destination

\begin{tabular}{llll}
\hline & r-value & p-value & Interpretation \\
\hline Gastronomic Experience & $0.881^{* *}$ & 0.000 & Highly Significant \\
Satisfaction & $0.814^{* *}$ & 0.000 & Highly Significant \\
\hline
\end{tabular}

Legend: Significant at $p$-value $<0.05$

Table 4.2 shows the relationship between the impacts of gastronomic tourism and gastronomy destination. Based from the table, the resulted r-values indicates an a strong direct correlation and the computed p-values were less than 0.01 alpha level. This means that there is a significant relationship exists and implies that the greater the impact, the better is the gastronomy destination. The impact of the gastronomic experience on the visitor has a crucial effect on satisfaction and, consequently, destination repetition. Thus, expanding the gastronomic offer in the Ilocos Region has become a key strategy that, in many cases, helps to place the destination in the minds of tourists. Similarly, in the tourism industry, facilities that are in demand by visitors to meet their needs must be provided with the customer's satisfaction as a guide. The gastronomy of the Ilocos Region in general is well-known, and its products are highly regarded by both domestic and international travelers. Furthermore, gastronomic tourism's widespread success has had an impact on local economies and has served as a catalyst for the growth of food tourism and culinary tourism. Consequently, there is a growing demand for professionals with expertise in the hospitality industry. Business organizations in the food and beverage sector, as well as conventional restaurants, food markets, and wine cellars, are all contributing to the rising demand.

\section{Conclusion and recommendation}

Gastronomic product has potential attractiveness in terms of preserving cultural heritage, adding destination authenticity value, marketing, motivation and gastronomy destination. Gastronomic tourism has impact in Ilocos region in terms of economic, social and cultural aspects. The respondents have an excellent gastronomic experience and they are satisfied with the food they eat when they visited the Ilocos region. There is highly significant relation exist between gastronomic products potential attractiveness, impacts of gastronomic tourism and gastronomy destination. Highly significant relationship also exists between impacts of gastronomic tourism and gastronomy destination.

It is recommended to create a strategic tourism development plan that cascades the sustainability of gastronomic tourism in Ilocos Region, revitalizing more traditional restaurants, wine cellars and food markets to further create and develop gastronomic routes for the tourists. Result of this study should be disseminated to the Department of Tourism Regional Office I to have a basis in crafting the said development plan. Establish digital marketing in the Region to enhance the local gastronomy making it more visible. This could be funded by the Department of Tourism Regional Office I. Introduce innovated products such as regional fusion of Philippine Cuisine to further develop a new set of authentic cultural products related to the gastronomy in Ilocos Region. Facilitate trainings and seminars such as Full Awareness Course to tour operators, travel agents and tour guides. This could be provided by the Regional Office of the Department of Tourism to better exploit the important existing synergies between the food and the cultural heritage that exists in Ilocos Region. Coordinate the promotional materials developed by the private sector (hotels, tour operators and restaurants) and other professional associations with the promotional materials developed by Department of Tourism Regional Office I in order to design better marketing strategies. Conduct future study using other variables such as gastronomic education and gastronomic research and training that can possibly an excellent study for the community. 


\section{References}

Aizega, M. J. (2019). Guidelines for the Development of Gastronomy Tourism. Spain: World Tourism Organization (UNWTO).

Buele, C.V. (2020) Gastronomic experience as a factor of motivation and satisfaction in coastal destinations. Journal of Environmental Management and Tourism. https://doi.org/10.14505/jemt.v11.6(46).03

Cruz, F.C., Tito, J.C., Galvez, J.C. \& Viruel, M.J. (2019) Gastronomic experiences of foreign tourists in developing countries: The case in the city of Oruro, Bolivia. Heliyon 5, $1-8$

De Castro, D. L., Aguiree, P.K., Andaya, I.O., Castro, A.D., Martinez, C.J., Soriano, S \& Felicin, S.S. (2019). Culinary tourism as a destination attraction in the province of Batangas, Philippines. Journal of Tourism and Hospitality Research. 15, $40-43$

de Albuquerque Meneguel, C. R., Mundet, L., \& Aulet, S. (2019). The role of a high-quality restaurant in stimulating the creation and development of gastronomy tourism. International Journal of Hospitality Management, 83, 220-228.

Forleo, M. \& Bernadett, G (2019) Creative cities of gastronomy: Towards relationship between city and countryside. International Journal of Gastronomy and Food Sciences. 4, 8- 12

Galvez, J.C., Granda, M.S., Guzman, T.L. \& Coronal J.R. (2017). Local gastronomy, culture and tourism sustainable cities: The behavior of the American tourist. Sustainable Cities and Society. 32, $604-612$

Galvez, J.C., Guzman T.L., Buiza, F.C. \& Viruel, M.J. (2017) Gastronomy is an element of attraction in a tourist destination: The case of Lima, Peru. Journal of Ethnic Food. 4, 254 - 261

Han, H (2019). What drives customer willingness to pay premiums for luxury gastronomic experiences at Michelin starred restaurant. International Journal of Hospitality Management 82, 209 - 219

Ivanov, S \& Seyituglo F. (2020). A conceptual study of the strategic role of gastronomy in tourism destinations. International Journal of Gastronomy and Food Science. 21. https://doi.org/10.1016/j.ijgfs.2020.100230

Kumar, G. M. (2019). Gastronomic tourism. A way of supplementing tourism in the Andaman and Nicobar Islands. Intl J of Gastronomy and Food Science. https://doi.org/10.1016/j.ijgfs.2019.100139

Long, L. (2018, January) Cultural politics in culinary tourism with ethnic foods. http://ethnic.net/articles/2018/1543-152321.pdf

Martin, J.C., Roman, C., Guzman, T.L. \& Cuadra, S. (2019). A fuzzy segmentation study of gastronomical experience. International Journal of Gastronomy and Food Sciences. 4, 6-9

Sahin, G. G. (2015). Gastronomy tourism as an alternative tourism: an assessment on the gastronomy tourism potential of Turkey. Intl J of academic research in business and social sciences, 5(9), 79-105.

Stanley, N. (2019, September). The retail landscape is rapidly changing as the retail experience itself evolves. Gastronomic experience is a key ingredient in the mix. https://blooloop.com/food-trends-gastronomic-experience/

United Nations World Tourism Organization (2016). 2nd World Forum on Gastronomy Tourism Underlines Relevance of Local Communities and Cultures. Targeted News Service; Washington, D.C.

United Nations World Tourism Organization (2017). 2nd UNWTO Report on Gastronomy Tourism: Sustainability and Gastronomy; Washington, D.C.

Widjaja, Y. I., Khalifa, G. S., \& Abuelhassan, A. E. (2020). The effect of Islamic attributes and destination affective image on the reputation of the halal tourism destination of Jakarta. Journal of Environmental Management and Tourism, 11(2), 299-313.

Wijaya, S. (2019). Indonesian food culture mapping: a starter contribution to promote Indonesian culinary tourism. Journal of Ethnic Foods, 6(1), 1-10.

World Tourism Organization and Basque Culinary Center (2019), Guidelines for the Development of Gastronomy Tourism, UNWTO, Madrid, DOI: https://doi.org/10.18111/9789284420957

Yousaf, A., Amin, I., \& Gupta, A. (2017). Conceptualising tourist-based brand-equity pyramid: an application of Keller brand pyramid model to destinations. Tourism and hospitality management, 23(1), 119-137. 
Etrata, R. M.

146 Consortia Academia Publishing (A Partner of Tourism Educators and Movers of the Philippines) 